\title{
A síndrome de Marfan e seus aspectos odontológicos: relato de caso e revisão da literatura
}

\author{
Dental aspects of Marfan syndrome: case report and review of the literature
}

\section{Carlos Eduardo Baraldi', Marcel Fasolo de Paris², Wanyce Miriam Robinson ${ }^{3}$}

\section{Resumo}

A síndrome de Marfan é uma doença do tecido conjuntivo, de caráter hereditário, com grande variabilidade de expressão clínica. Afeta fundamentalmente os sistemas esquelético, cardiovascular e ocular. Sua etiologia está relacionada a mutações no gene da fibrilina-1 (FBN1), ${ }^{*}$ localizado no cromossomo 15 (15q21.1). As alterações dento-faciais presentes na síndrome, além de outras características relacionadas ao sistema estomatognático, tornam importantes o reconhecimento desta condição e o adequado manejo do paciente pelo profissional da Odontologia. O objetivo deste artigo é revisar a literatura que relaciona a SM à Odontologia.

Palavras-chave: Síndrome de Marfan, Odontologia, Portadores de Necessidades Especiais.

\section{Abstract}

The Marfan syndrome is an inheritable connective tissue disease, with variable clinical expression. The disease affects specially the skeletal, cardiovascular and ocular systems. Mutations in the gene coding for fibrillin on chromosome 15 (FBN1) are known to cause Marfan syndrome. The dentofacial abnormalities present on the disease, as well as other stomatognathic characteristics, make the recognizing and correct managing of these patients important. This paper resumes some of the most important aspects about SM related to Dentistry.

Keywords: Marfan syndrome; Dentistry; Disabled persons.

\section{Introdução}

A síndrome de Marfan - MIM \#154700 (MARFAN, 2008) - é uma das mais importantes doenças genéticas do tecido conjuntivo, seguida pela osteogênese imperfeita, pelas síndromes de Stickler e pelo Ehlers-Danlos (CALLEWAERT et al., 2008). Tais doenças são causadas por alteração na síntese do colágeno. Acredita-se que a SM deva-se a uma mutação no gene que codifica a proteína fibrilina-1 (FBN1), localizado no braço longo do cromossomo 15 (15q21.1). Trata-se de um gene grande (110Kb) e segmentado (65 éxons). Muitas mutações estão descritas, sendo peculiares a cada família envolvida. Nem todas podem ser detectadas através de exames laboratoriais (MARFAN, 2008).

A patologia foi descrita por Antoine Marfan, reconhecido como o primeiro Professor de Pediatria da França, em 1896 (DE PAEPE et al., 1996; CALLEWAERT et al., 2008). A incidência é estimada em 1:10.000 indivíduos, sendo a maior parte dos casos familiais, com aproximadamente $5 \%$ dos casos devendo-se a mutações novas em indivíduos sem história familiar. Não se conhecem fatores etiológicos para que tal ocorra. Não há predileção por raça ou sexo. A expressividade da doença é variável, tanto interfamilial quanto intrafamilial. A doença já foi observada em diversas regiões geográficas. O tipo de herança é autossômica dominante, tendo o gene alta penetrância, mas expressividade fenotípica variável. A doença é pleiotrópica, envolvendo principalmente três sistemas: esquelético, ocular e cardiovascular (CV). A expectativa de vida
${ }_{1}^{1}$ Professor-Adjunto da Faculdade de Odontologia da Universidade Federal do Rio Grande do Sul, Porto Alegre, RS

${ }^{2}$ Professor-Adjunto da Faculdade de Odontologia da Universidade Federal do Rio Grande do Sul, Porto Alegre, RS

${ }^{3}$ Professora Aposentada do Departamento de Genética - IBC - Universidade Federal do Rio Grande do Sul, Porto Alegre, RS

* Os autores declaram que não há conflitos de interesses na redação ou publicação deste artigo.

Correspondência: Carlos Eduardo Baraldi

Endereço: Rua Guararapes, 517/602 - Petrópolis - 90690340 - Porto Alegre - RS Fone: 51 9971-1054

E-mail: cbaraldi@uol.com.br

destes pacientes é menor do que a da população normal, havendo relatos de morte súbita devido a complicações cardiovasculares (DE PAEPE et al., 1996; CALLEWAERT et al., 2008).

\section{Diagnóstico}

O diagnóstico da SM é clínico, baseado nos sinais e sintomas da doença resumidos no Quadro 1. Os métodos laboratoriais para o mesmo não estão disponíveis para utilização clínica, servindo mais para propósitos de investigação científica. Pacientes que não apresentem a mutação no gene da FBN1, mas preencham os critérios clínicos, podem ser classificados como casos da doença.

Quadro 1. Principais características clínicas da síndrome de Marfan.

\begin{tabular}{|c|c|}
\hline Músculo-esqueléticas & Craniofaciais \\
\hline estatura elevada & dolicocefalia \\
\hline membros longos & deficiência transversal da maxila \\
\hline segmento inferior maior que o superior & palato alto e profundo \\
\hline envergadura maior que estatura & prognatismo mandibular \\
\hline aracnodactilia & retrognatia maxilar \\
\hline tórax longo e deformado & má oclusão \\
\hline peito escavado ou carenado & mordida cruzada posterior \\
\hline escoliose & apinhamentos e retenções dentárias \\
\hline frouxidão ligamentar & dentes longos e estreitos \\
\hline pé plano & $\begin{array}{l}\text { disfunções temporomandibulares } \\
\text { subluxações do côndilo mandibular }\end{array}$ \\
\hline luxações recorrentes da patela & luxações recorrentes da mandíbula \\
\hline Oculares & Outras \\
\hline Ectopia lentis & ectasia dural \\
\hline Miopia & pneumotórax espontâneo \\
\hline \multirow[t]{2}{*}{ íris hipoplásica } & maior incidência de SAHOS \\
\hline & alterações neuropsicológicas \\
\hline Cardiovasculares & instabilidade do tórax \\
\hline prolapso mitral & hérnias e de estrias da pele \\
\hline anomalias das artérias aorta e pulmonar & maior prevalência de enxaqueca \\
\hline
\end{tabular}


De Paepe et al. (1996) revisaram os critérios diagnósticos para a SM, classificando-os em maiores e menores. Consideraram a presença de familiar de primeiro grau afetado (pai/mãe, irmãos), bem como a identificação, no paciente, da mutação conhecida do gene citado, como sinais maiores da doença.

No sistema esquelético, é clássica a descrição de estatura corpórea elevada, com membros longos, sendo o segmento inferior maior do que o superior, e a envergadura maior do que a estatura. A presença de dedos longos (aracnodactilia) é característica (Figura 1). O tórax é longo, geralmente deformado, com a presença de peito escavado (Figura 2) ou carenado. Escoliose pode estar presente, bem como protusão do acetábulo. Um sinal clínico menor é a frouxidão ligamentar, podendo levar à ocorrência de pé plano, a luxações recorrentes da patela ou da mandíbula. A presença de quatro a oito alterações menores é considerada como uma alteração maior (DE PAEPE et al., 1996; CALLEWAERT et al., 2008). As alterações esqueléticas peculiares levaram à relação anedótica de personalidades históricas à síndrome, como o ex-presidente norteamericano Abraham Lincoln e o virtuoso violinista Paganini, os quais viveram antes mesmo da descrição da doença por Marfan.

As alterações oculares são frequentes, sendo a subluxação do cristalino (ectopia lentis) considerada um sinal maior (DE PAEPE et al., 1996; CALLEWAERT et al., 2008). O comprimento exagerado do globo ocular pode estar presente, contribuindo para miopia. O descolamento de retina pode ocorrer, provocando a alteração oftalmológica mais grave da síndrome. A incidência de catarata e glaucoma é maior do que na população geral. A íris pode ser hipoplásica, dificultando a midríase, complicando não só o diagnóstico, como também eventuais tratamentos oftalmológicos que necessitem dilatação pupilar. Sallum, Chen e Perez (2002) avaliaram as alterações oftalmológicas de 46 pacientes com SM, tendo observado alterações oculares em $89,1 \%$ destes. Concluíram pela importância do conhecimento e diagnóstico da síndrome, contribuindo para o tratamento precoce da mesma. Destacaram a importância de centros especializados multidisciplinares para atendimento destes pacientes, devido ao amplo número de órgãos afetados, ocasionando diferentes complicações ao longo da vida dos doentes.

As manifestações CV são as que inspiram maior preocupação, devido à sua gravidade. Anomalias da artéria aorta, como dilatação ou dissecção da região ascendente (sinal maior), são frequentes. Dilatação da artéria pulmonar e alterações da artéria aorta descendente podem manifestar-se com o avançar da idade (DE PAEPE et al., 1996; SALLUM; CHEN; PEREZ, 2002). Prolapsos da válvula mitral, com regurgitação, podem levar à insuficiência mitral, além de ser fator de risco para endocardites bacterianas. Assim, o tratamento dentário e a manutenção de níveis adequados de saúde bucal são elementos importantes para a prevenção de quadros infecciosos deste tipo, de grande impacto na morbimortalidade (DE COSTER et al., 2002).

Outras alterações podem se manifestar, como o pneumotórax espontâneo, a presença de hérnias e de estrias da pele não relacionadas à perda de peso. Estas estão associadas à flacidez do tecido conjuntivo. A instabilidade do tórax é um fator a considerar frente à indicação de procedimentos anestésicos gerais. Alguns pacientes apresentam alterações neuropsicológicas, como déficit de atenção e dificuldades de aprendizagem. Estes aspectos, porém, necessitam de maiores estudos para serem correlacionados à síndrome (PEREZ, 2001; SALLUM; CHEN; PEREZ, 2002). Sua presença pode inclusive conduzir ao diagnóstico diferencial de outras síndromes (CALLEWAERT et al., 2008).

No sistema nervoso, a ectasia dural (alargamento do tubo neural) é considerado sinal maior da SM (DE PAEPE et al., 1996; CALLEWAERT et al., 2008), diagnosticado através de exames de imagem (tomografia computadorizada ou ressonância magnética). Os sintomas podem incluir dor lombar, cefaleia, disfunção intestinal ou urinária. Trata-se, no entanto, de uma condição frequentemente assintomática, especialmente em seus estágios iniciais. Isto dificulta sua avaliação, especialmente com finalidades meramente científicas, considerando o alto custo dos exames de imagem, bem como a exposição a radiações ionizantes (TC). Fica assim prejudicado o maior entendimento desta condição.

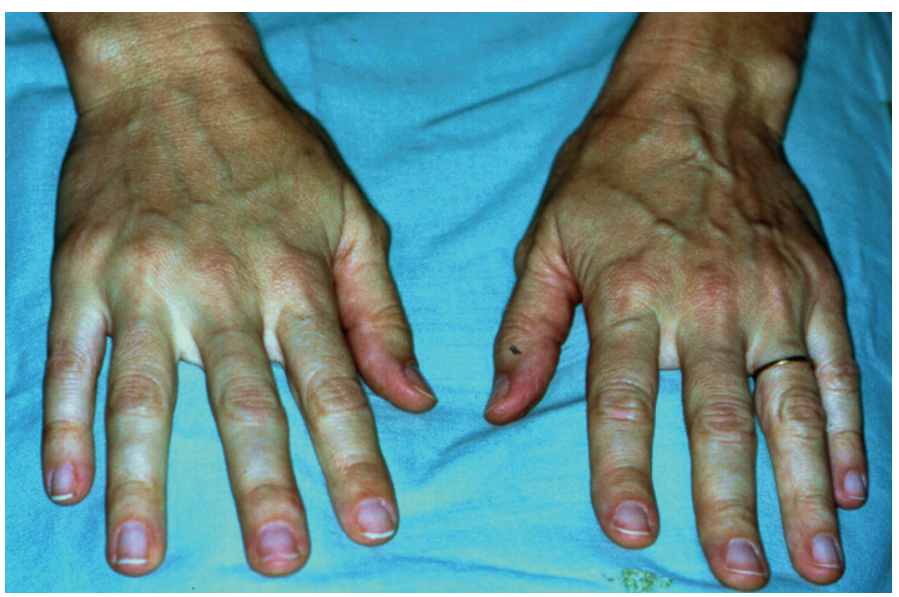

Figura 1. Aracnodactilia.

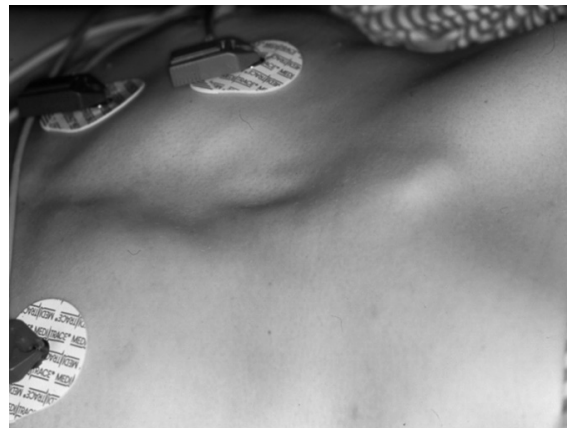

Figura 2. pectus escavatum.

\section{Características bucomaxilofaciais}

As alterações craniofaciais foram classificadas por De Paepe et al. (1996) como critérios menores para o diagnóstico. São muito importantes, contudo, na prática clínica odontológica, pois determinam uma série de necessidades de tratamento para melhora das funções de mastigação, de respiração, de fonação e de deglutição. As descrições clássicas incluem a dolicocefalia, associada a anomalias com deficiência transversal da maxila, palato alto e profundo, má oclusão, prognatismo mandibular e excesso vertical facial (Figuras 3 e 4). Tais alterações estão associadas a más oclusões, com mordidas cruzadas, apinhamentos e retenções dentárias, como a de caninos superiores (Figura 5). Disfunções temporomandibulares são mais frequentes do que na população em geral. Os dentes tendem a ser mais longos e estreitos.

Westling, Mohlin e Bresin (1998) avaliaram as manifestações crânio-faciais e oclusais de pacientes portadores de SM, comparando-os a controles normais. Em sua amostra, 36\% dos pacientes receberam diagnóstico após o tratamento ortodôntico, chamando a atenção para a possibilidade do diagnóstico de tal entidade pelo cirurgião-dentista. Mais de $80 \%$ dos indivíduos da amostra apresentavam más oclusões descritas como severas, sendo o apinhamento dentário maxilar e mandibular frequente. A análise cefalométrica lateral demonstrou maiores índices de retrognatia nos pacientes sindrômicos, causada por menor comprimento maxilar, no plano sagital. Uma menor altura do ramo mandibular também se mostrou associada.

A respeito de alterações dentárias, Ortolan, Dualibi e Dualibi (2000) descreveram um caso de paciente portador da SM, observando atraso de irrompimento dentário, presença de dentes 
supranumerários mandibulares e a ocorrência de implantação anormal dos mesmos. De Coster et al. (2002), em um estudo de caso-controle, observaram ser a experiência de cáries, a presença de anomalias dentinárias (anomalias da cavidade pulpar, nódulos pulpares e alterações morfológicas radiculares) e esmalte hipoplásico, bem como a incidência de doenças do periodonto, maior nos pacientes afetados pela SM, na amostra estudada. Sugeriram uma correlação com a alteração do colágeno, sem descartar possíveis alterações hereditárias da dentina nas famílias estudadas, bem como a influência socioeconômica na prevalência de doenças bucais, já que as demais complicações da síndrome podem conduzir ao desinteresse pela saúde bucal. A manutenção desta, no entanto, é reconhecida como fator de sobrevida nestes pacientes, dado seu alto risco de endocardite bacteriana.

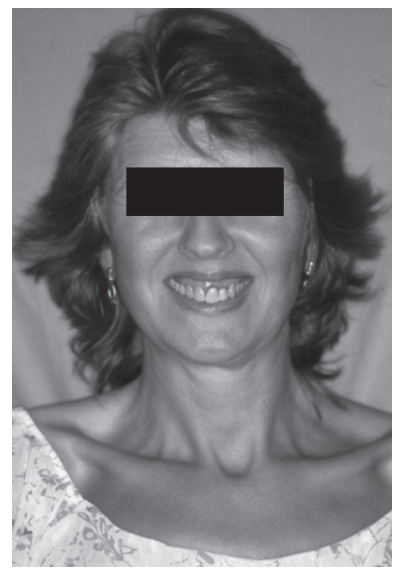

Figura 3. Aspecto frontal facial. Observar a face longa e estreita, com excesso vertical maxilar.

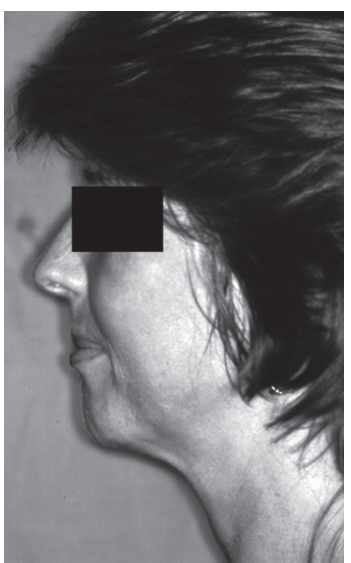

Figura 4. Aspecto lateral da face. Observar o excesso de altura facial e a retrusão discreta do terço facial médio.

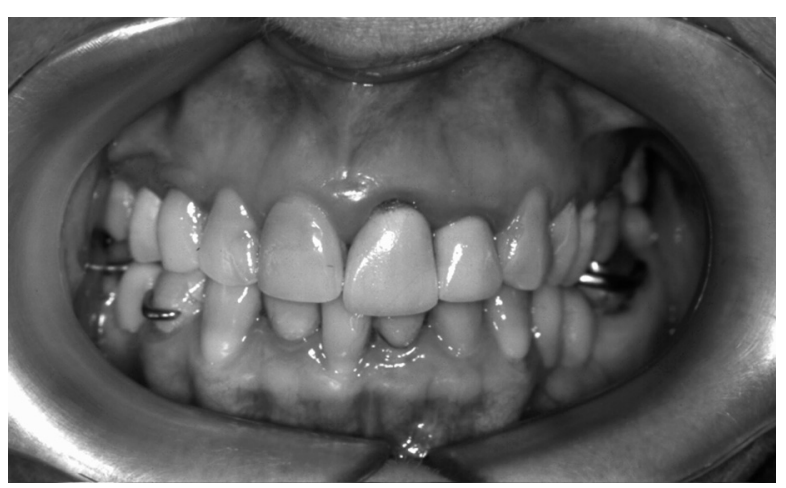

Figura 5. Aspecto da má oclusão, com tendência para estreitamento dos arcos dentários e excesso vertical maxilar.

\section{Aspectos morfofuncionais das anomalias bucomaxilofaciais na SM}

Os portadores da SM apresentam graus variáveis de distúrbios respiratórios obstrutivos altos. Estes achados podem estar relacionados diretamente à deficiência do tecido conjuntivo, bem como serem consequentes às alterações morfológicas bucomaxilofaciais presentes.

Cistulli e Sullivan (1993) observaram maior incidência de ronco e apneia obstrutiva em pacientes portadores da síndrome, em estudos de caso-controle, comparados a voluntários normais. Observaram maior colapsabilidade das vias aéreas superiores de pacientes com SM, comparados a controles normais (CISTULLI; SULLIVAN, 1995). Tal característica pode explicar os maiores índices de apnéias obstrutivas do sono observados nos primeiros, podendo ter relação com a deficiência do tecido conjuntivo, já que o biotipo do paciente portador da síndrome - magro, alto, longilíneo e jovem - difere daquele do paciente típico com apneia obstrutiva obeso, com o pescoço curto e de meia-idade.

A possibilidade de maior resistência nasal nos pacientes com SM, devido às alterações anatômicas da maxila (deficiência transversal e palato profundo), foi avaliada por Cistulli et al. (1996). Estes relacionaram os dados obtidos através de rinomanometria posterior, com medidas da morfologia maxilar em modelos de gesso, em pacientes portadores da SM e voluntários normais. Observaram alterações da maxila, com diâmetro transversal menor, bem como maior profundidade de palato, além de maior resistência nasal, nos indivíduos afetados. A análise estatística demonstrou correlação moderada entre a resistência nasal e o diâmetro da maxila, contribuindo para a tese proposta previamente (CISTULLI; SULLIVAN, 1993) que os altos índices de apneia obstrutiva dos portadores de SM poderiam estar relacionados à sua anatomia maxilar típica.

Em outro estudo, Cistulli, Gotsopoulos e Sullivan (2001) correlacionaram alterações craniofaciais e índice de apneia obstrutiva de pacientes portadores da SM. Utilizaram, para tal, exames de polissonografia e análise cefalométrica lateral, testando suas hipóteses com teste de regressão. Observaram alta frequência de alterações cefalométricas, como a retrusão da maxila e da mandíbula, o ângulo mandibular aumentado, bem como excesso de altura facial. Tais alterações mostraram-se ainda significativamente relacionadas a altos índices de apneia obstrutiva. Discutiram, porém, que não se conhece profundamente a etiologia das alterações craniofaciais da $\mathrm{SM}$, podendo ser as mesmas derivadas da alteração genética, bem como alterações do crescimento semelhantes às de pacientes com obstrução nasal crônica e respiração bucal (dolicocefalia). Sugeriram mais estudos para relacionar alterações morfológicas faciais ao defeito genético determinante da SM.

\section{A síndrome de Marfan e as dores orofaciais}

Existem ainda evidências sugestivas de maior prevalência de distúrbios temporomandibulares em pacientes portadores da síndrome. De maneira similar aos distúrbios obstrutivos respiratórios, estas alterações podem ser devidas primariamente ao distúrbio do colágeno, com maior frouxidão articular, bem como ter alguma contribuição da morfologia dentofacial desfavorável. Bauss et al. (2004) avaliaram a prevalência de sinais e os sintomas de disfunção temporomandibular (DTM) em uma amostra de 281 pacientes, por meio de questionários, complementados por exame clínico e ressonância magnética de ATMs em 21 destes. Houve prevalência de $51,6 \%$ de sintomas temporomandibulares, sendo os relacionados à subluxação os mais frequentes. Um total de $98(34,9 \%)$ pacientes já havia se submetido a algum tratamento para DTM, boa parte incluindo cirurgias articulares. Estes resultados sugerem que a DTM é um importante problema de saúde dentre os portadores da síndrome. 
Um recente estudo de caso-controle por Vis et al. (2008) encontrou uma prevalência maior de enxaqueca em 309 pacientes com SM, comparados a 102 controles. Os números foram ainda maiores naqueles que haviam sido submetidos à cirurgia aórtica, com maior prevalência de enxaqueca com aura. Este tipo de cirurgia é realizado em casos de alterações aórticas mais expressivas. Não está claro se estes achados se devem a alterações aórticas, do endotélio vascular ou mesmo neurológicas, relacionadas à síndrome.

\section{Discussão}

Apesar das características marcantes da SM, as inúmeras possibilidades de diagnóstico diferencial, além dos critérios diagnósticos complexos, sugerem como prudente o aconselhamento genético para o fechamento do diagnóstico. Isto é especialmente importante em pacientes selecionados para pesquisa. Tal orientação é ainda relevante para o paciente, para que este exerça suas decisões esclarecido sobre as implicações da doença.

A identificação dos pacientes portadores da SM, bem como a determinação de órgãos e/ou sistemas comprometidos, prévio ao tratamento odontológico, é de importância devido ao risco elevado de complicações $\mathrm{CV}$, inclusive endocardite bacteriana. $\mathrm{O}$ conhecimento dos sinais e sintomas da síndrome pelo cirurgião-dentista é importante, pois o mesmo pode ser o profissional responsável pelo diagnóstico da doença, dada a grande quantidade de alterações bucomaxilofaciais presentes.

Para o tratamento odontológico invasivo, o uso de anestésicos locais contendo vasoconstrictores adrenérgicos (adrenalina, noradrenalina) deve ser racional. Os vasoconstrictores não adrenérgicos prilocaína e levonordefrina podem ser indicados, bem como soluções anestésicas sem vasoconstrictores. Deve ser encorajado o controle do estresse durante as sessões, a duração curta das mesmas, bem como o monitoramento da pressão arterial e da frequência cardíaca durante $o$ atendimento.

As alterações bucomaxilofacias presentes na síndrome, especialmente a deficiência transversal da maxila, contribuem para a ocorrência da síndrome das apneias/hipopneias obstrutivas do sono (SAHOS) nestes pacientes. Estudos são necessários para avaliar se sua correção através de técnicas ortopédicas, ortodônticas ou cirúrgico-ortodônticas, pode contribuir para a maior (e melhor) sobrevida destes pacientes, ao propiciar correção anatômica bucomaxilofacial e consequente melhora das condições de permeabilidade da via aérea superior. A prevenção ou diminuição da incidência e da gravidade da SAHOS pode contribuir para o aumento da sobrevida, dada a contribuição desta entidade no desenvolvimento de alterações CV, sistema onde a SM provoca alterações de maior risco de morte. As correções dentofaciais podem ainda contribuir para diminuir a maior prevalência de sintomas temporomandibulares associada à síndrome.

\section{Conclusão}

Mais estudos são necessários para identificar de forma mais precisa as alterações bucomaxilofaciais da SM, quais delas estariam relacionadas à alteração do gene codificador da proteína fibrilina-1 e quais poderiam ser de causa ambiental. O melhor entendimento desta etiopatogênese poderá orientar decisões terapêuticas para prevenção e correção de tais alterações.

\section{Referências}

BAUSS, O. et al. Temporomandibular Joint Dysfunction in Marfan Syndrome. Oral Surg. Oral Med. Oral Pathol. Endod., St. Louis, v. 97, n. 5, p. 592-598, May 2004.

CALLEWAERT, B. et al. Ehlers-Danlos Syndromes and Marfan Syndrome. Best Pract. Res. Clin. Rheumatol., Amsterdam, v. 22, n. 1, p. 165-189, Mar. 2008.

CISTULLI, P. A. Influence of Maxillary Constriction on Nasal Resistance and Sleep Apnea Severity in Patient's with Marfan's Syndrome. Chest, Chicago, v. 110, n. 5, p. 1184-188, Nov. 1996.

CISTULLI, P. A.; GOTSOPOULOS, H.; SULLIVAN, C. E. Relationships between Craniofacial Abnormalities and Sleep-disordered Breathing in Marfan Syndrome. Chest, Chicago, v. 120, n. 5, p. $1455-1460$, Nov. 2001

CISTULLI, P. A.; SULLIVAN, C. E. Sleep Apnea in Marfan's Syndrome: Increased upper Airway Collapsibility During Sleep. Chest, Chicago, v. 108, n. 3, p. 631-635, Sept. 1995.

CISTULLI, P. A.; SULLIVAN. C. E. Sleep Disordered Breathing in Marfan's Syndrome. Am. Rev. Respir. Dis., Baltimore, v. 147, n. 3, p. 645-648, Mar. 1993.

DE COSTER, P. J. A. et al. Oral Manifestations of Patients with Marfan Syndrome: a Case-control Study. Oral Surg. Oral Med. Oral Pathol. Oral Radiol. Endod., St. Louis, v. 93, n. 5, p. 564-572, May 2002.

DE PAEPE, A. et al.Revised Diagnostic Criteria for the Marfan Syndrome.Am.J.Med.Genet.,NewYork, v.62,n.4, p.417-426, Apr.1996.

MARFAN Syndrome: MIM 154700. Baltimore: Johns Hopkins University, 2008. Disponível em http://www.ncbi.nlm.nih.gov/omim/.

ORTOLAN, C. M.; DUALIBI, S. E.; DUALIBI, M. T. Diagnóstico, Planejamento e Preservação de um Paciente Portador de Síndrome de Marfan - Relato de Caso Clínico. Rev. Paulista Odontol., São Paulo, v. 22, n. 3, p. 22-27, maio/jun. 2000.

PEREZ, A. B. Principais Doenças do Tecido Conjuntivo. In: Carakushansky, G. Doenças Genéticas em Pediatria. Rio de Janeiro: Guanabara-Koogan, 2001. [Cap. 34].

SALLUM, J. M. F.; CHEN, J.; PEREZ, A. B. A. Anomalias Oculares e Características Genéticas na Síndrome de Marfan. Arq. Bras. Oftalmol., São Paulo, v. 65, n. 6, p. 623-628, nov./dez. 2002.

VIS, J. C. et al. Increased Prevalence of Migraine in Marfan Syndrome. Int. J. Cardio., Amsterdam, v. 136, n. 3, p. 330-334, Aug. 2009.

WESTLING, L.; MOHLIN, B.; BRESIN, A. Craniofacial Manifestations in the Marfan Syndrome: Palatal Dimensions and a Comparative Cephalometric Analysis. J. Craniofac. Genet. Dev. Biol., New York, v. 18, n. 4, p. 211-218, Oct./Dec.1998. 